\title{
Daily headaches due to medication overuse
}

Eric Eross

\begin{abstract}
Headaches are one of the most common problems that cause people visit a physician. Some people who have headaches off and on can develop a different type of daily headache that is caused by some of the medications used to treat their original, episodic headache. This is called medication overuse headache $(\mathrm{MOH})$.
\end{abstract}

\section{Treatment for $\mathrm{MOH}$}

The main treatment for $\mathrm{MOH}$ is to stop the medication that is being overused. Katsarava and colleagues in this issue of Neurology studied a group of 96 patients with daily headaches caused by medication overuse that had over a 50\% reduction in headache days 1 month after withdrawal of medication. Of this group, $71 \%$ had migraines, $14 \%$ had tension-type headaches, and $15 \%$ had a combination of the two. The medications being overused by patients were divided into three groups: pain medication $(48 \%)$, ergots $(13 \%)$, and triptans (39\%). Pain medications are used to treat the pain symptoms of the headache. The ergots and triptan drugs are used to abort or stop the headache but are not pain medications.

\section{Risk Factors for MOH Relapse}

Patients were followed-up at both 6 and 12 months after withdrawal of their medication. Seventy-nine of the original patients were available for questioning at 12 months. Four out of 10 patients relapsed (went back to having daily headaches) at one year's time. Patients with combined headaches (both migraine and tension-type) relapsed most frequently (77\% of the time), followed by tension-type headaches (73\%) and migraine headaches $(22 \%)$. That is, patients with isolated migraine headaches were least likely to suffer relapse. Those patients using analgesics were the most likely $(58 \%)$ to relapse, followed by ergots (20\%) and then triptans (19\%).

The authors concluded that both headache type and medication type can be used to predict who is most likely to go back to having daily headaches. Patients with both migraine and tension-type headaches and those overusing analgesics initially are at greatest risk. Those with migraine only and patients overusing triptans are least likely to relapse. A distinct possibility, not mentioned by the authors, is that those overusing analgesics were more likely to relapse because they could get as much of this medication as they desired. This is compared with the triptans, which are often limited to patients because they are expensive and require a prescription.

\section{Prevention of $\mathrm{MOH}$}

Despite the interesting findings from this study, I encourage patients I treat for headache problems to focus on the frequency of their headache medication use and not the type of medication they are using or the type of headache they have. Regardless of the type of headache problem that you have, if you find yourself using pain medication, ergots, or triptans three or more days per week, you need to consider the possibility that you may have or will get $\mathrm{MOH}$. Headaches that are occurring this frequently need to be brought to the attention of your physician. You may need to be placed on a prophylactic medication, a unique group of medications designed to prevent headaches. Such a simple change could dramatically improve the quality of your life.

\section{What Is a Headache?}

Headaches are the result of pain signals caused by interactions between the brain, blood vessels, and nerves. The pain comes from irritated nerves in the blood vessels and muscles of the head. The reason for the nerve irritation is not known, but these irritated nerves send signals to the brain that are interpreted as a headache. Headaches are three times more common in women than men. If treated correctly, over $85 \%$ of headaches will respond to treatment, so it is important to seek medical care for a headache problem.

\section{What Are the Types of Headaches?}

There are two basic types of headaches: those that are a symptom of a serious medical illness and those that are not. Headaches not caused by a serious medical illness are more common and are described here.

Migraine headaches. Approximately 28 million Americans suffer from migraines. With migraines the pain is usually severe, throbbing, and on one side of the head. There is also upset stomach with vomiting and sensitivity to loud noises and bright lights. Migraines last between 4 and 72 hours and usually occur once to several times a month. If there are more than fifteen days of headaches per month, 
the condition is called chronic migraine, which is a type of chronic daily headache.

Tension-type headaches. Tensiontype headaches can be another cause of chronic daily headaches. With tension-type headaches the pain is a squeezing band-type feeling around the head. Usually, tensiontype headaches are less severe than migraines and may last as short as 30 minutes or as long as 1 week.

What Causes Daily Headaches? Patients can go from having headaches off and on to having chronic daily headaches. This can happen for unexplained reasons. However, research suggests that it may be the pain medications that a patient takes for headaches that cause this to occur. The medication that helpstoday's headache may actually cause tomorrow's headache. This is called a medication overuse headache $(\mathrm{MOH})$. Any medication that is taken to treat an individual headache attack is thought to be able to cause $\mathrm{MOH}$. This includes pain medications (even over-thecounter) and other prescription medications if taken 3 or more days per week.

Treatment for Medication Overuse Headaches. Stopping the culprit medication is the key! It may take weeks or several months after the withdrawal of this medication until a patient begins to experience headache relief. Even then, relapse is common with medication overuse over time and a return to the chronic daily headaches.
Another treatment option is to begin a daily medication that is designed to prevent headaches in the first place. Usually if patients are having more than 10 days of headaches per month, preventative treatment is recommended to decrease the chances of triggering daily headaches.

\section{For More Information:}

American Academy of Neurology at www.aan.com

American Headache Society at www.ahsnet.org

National Headache Foundation at www.headaches.org 


\title{
Neurology
}

\author{
Daily headaches due to medication overuse \\ Eric Eross \\ Neurology 2003;60;E8-E9 \\ DOI 10.1212/01.WNL.0000072526.35698.0A
}

This information is current as of May 27, 2003

\section{Updated Information \&}

Services

Permissions \& Licensing

Reprints including high resolution figures, can be found at:

http://n.neurology.org/content/60/10/E8.full

Information about reproducing this article in parts (figures,tables) or in its entirety can be found online at:

http://www.neurology.org/about/about_the_journal\#permissions

Information about ordering reprints can be found online:

http://n.neurology.org/subscribers/advertise

Neurology ${ }^{\circledR}$ is the official journal of the American Academy of Neurology. Published continuously since 1951, it is now a weekly with 48 issues per year. Copyright. All rights reserved. Print ISSN: 0028-3878. Online ISSN: 1526-632X.

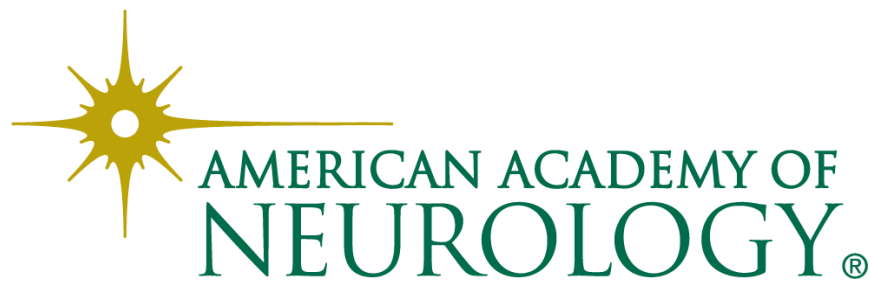

